\title{
A single-centered, retrospective cohort study of critically ill COVID-19 patients: Is the heart at risk?
}

Annie Loraine E. Khan, MD, ${ }^{1}$ Glenn Rose B. Advincula, MD, ${ }^{2}$ Francis Charles L. Fernandez, MD, ${ }^{3}$ Simonette Kristine T. Sawit, MD4

${ }^{1}$ Cardiology, The Medical City, Metro Manila, Philippines

${ }^{2}$ Cardiology-Advanced Heart Failure, The Medical City, Metro Manila, Philippines

${ }^{3}$ Cardiology-Interventional, The Medical City, Metro Manila, Philippines

${ }^{4}$ Cardiology-Advanced Cardiac Imaging, The Medical City, Metro Manila, Philippines

Corresponding Author: Annie Loraine E. Khan, MD

Email: annie_loraine2000@yahoo.com

Cellphone: +639177229695

\section{ABSTRACT}

\section{OBJECTIVE}

The Philippines has the highest COVID-19 mortality rate by country (per million) in South East Asia. We aim to explore predictors of mortality among critically ill COVID-19 patients.

\section{METHODS}

This single-centered, retrospective cohort study included consecutive patients with confirmed COVID-19 infection and acute respiratory distress syndrome requiring mechanical ventilation and intensive care unit (ICU) admission at The Medical City hospital from March 6 to March 31, 2020. Clinical data were obtained from medical records review and compared between survivors and non-survivors.

\section{RESULTS}

Among 30 patients (mean age $65 \pm 3$ years, interquartile range $32-86 ; 63 \%$ male), hypertension (67\%), diabetes mellitus (45\%), hyperlipidemia (40\%) and smoking history (30\%) were common. Those with echocardiogram showed no left ventricular dysfunction except 1 (preexisting heart failure), despite elevated troponin and NT-pro BNP. All had sepsis; $87 \%$ had septic shock. Twenty two (73\%) died, 6 (20\%) discharged improved, 1 (3\%) transferred to another hospital (outcome unknown), and 1 (3\%) still admitted. Mean duration from ICU admission to death was 13 days for non-survivors. Use of norepinephrine plus vasopressin and unfractionated heparin (UFH) for thromboprophylaxis were significantly higher among non-survivors versus survivors. There was a nonsignificant trend towards a higher mean troponin and NT-proBNP among non-survivors versus survivors.

\section{CONCLUSION}

We report that use of norepinephrine plus vasopressin and UFH for thromboprophylaxis were predictors of mortality among critically ill COVID-19 patients. Mean survival time of non-survivors is likely to be 13 days after ICU admission. Elevated troponin and NT-proBNP were not associated with increased mortality.

\section{INTRODUCTION}

Coronavirus disease 2019 (COVID-19) is an infectious disease caused by Severe Acute Respiratory Syndrome Coronavirus-2 (SARS-CoV-2), unknown before the outbreak began in Wuhan, China, in December 2019. ${ }^{1}$ The first case of COVID-19 in Manila, Philippines was reported on January 30, 2020. On March 7 , the first local transmission of COVID-19 was confirmed..$^{1-2}$ In the South East Asia region, the Philippines continues to have the highest mortality rate by country (per million) and ranks first in the total number of confirmed COVID-19 cases despite early border closure and community quarantine. ${ }^{3}$

While in the majority of COVID-19 infections, clinical symptoms may be mild, nearly $20 \%$ of patients develop severe to critical illness. ${ }^{4-6}$ Among all patients, a range of $3 \%$ to $17 \%$ developed acute respiratory distress syndrome (ARDS) compared to a range of $20 \%$ to $42 \%$ for hospitalized patients and $67 \%$ to $85 \%$ for patients admitted to the intensive care unit (ICU). ${ }^{7-12}$ Patients admitted to the ICU have a reported mortality from 39\% to $72 \%$ depending on the study. ${ }^{9,11,13-14}$ Cardiovascular complications, including myocardial injury and myocarditis, acute myocardial infarction, heart failure, dysrhythmias and venous thromboembolic events can be a significant contributor to the mortality associated with COVID-19. 4,9-10,13,15

To our knowledge, no previous study has been done locally to explore predictors for in-hospital mortality in COVID-19 patients. Understanding the clinical course and awareness of cardiovascular complications may help guide clinical decision making in ICU care and treatment.

\section{METHODS}

\section{STUDY DESIGN AND POPULATION}

This single-centered, retrospective cohort study included 30 consecutive patients with critical COVID-19 illness admitted to the ICU at The Medical City, a tertiary care hospital (Metro Manila, Philippines) from March 6 to March 31, 2020. COVID-19 was confirmed by a positive result on reverse transcriptase polymerase chain assay of a nasopharyngeal swab or endotracheal aspirate obtained in accordance with Centers for Disease Control and Prevention (CDC) guidelines. ${ }^{16}$ ARDS was defined according to the Berlin Definition. ${ }^{17}$ Critical COVID-19 illness has been previously defined. ${ }^{4,18}$

\section{DATA COLLECTION}

Institutional Review Board approval and waiver of informed consent were granted. Data on demographics, baseline clinical characteristics, initial laboratory and imaging findings, ICU therapies and outcomes were obtained by chart review from electronic medical records using a standardized case report form. Anonymized data were entered into a database designed 
for the study. We looked at mortality or hospital discharge after ICU admission. ICU therapies and outcomes were followed until time of death or hospital discharge. Sepsis and septic shock were defined according to the Surviving Sepsis Guidelines. ${ }^{19}$

\section{STATISTICAL ANALYSIS}

Our study follows the STROBE (Strengthening the Reporting of Observational Studies in Epidemiology) guidelines. ${ }^{20}$ Data were summarized using descriptive statistics. Continuous variables were described as mean \pm standard deviation (SD) and other measures of central tendency; likewise comparisons were determined using Student's $t$ test as appropriate, or Fisher exact test for categorical variables on survivors and non-survivors. Univariate and multivariate logistic regression were performed to explore the association of clinical variables and risk of mortality. Statistical significance was set at a p-value $<0.05$. Analysis was performed with Stata version 13 (StataCorp)

\section{RESULTS}

\section{BASELINE CLINICAL CHARACTERISTICS}

Baseline clinical characteristics of the 30 patients are shown in Table 1. The mean age was $65 \pm 3$ years (interquartile range 32 to 86$) ; 63 \%$ were male. The most common comorbidities were hypertension (67\%), diabetes mellitus (45\%), and hyperlipidemia $(40 \%)$. Ten (30\%) were current or ex-smokers. Among those with hypertension $(n=20)$, more than half were taking at least 2 antihypertensive agents, $80 \%$ were renin-angiotensin-aldosterone system (RAAS) blockers. Half of patients were overweight. The most common symptom on admission to the hospital was dyspnea (63\%). The mean duration of symptoms prior to admission was $7 \pm 1$ days. Seventeen (57\%) had documented fever and 16 (53\%) had elevated respiratory rate upon examination.

\section{LABORATORY AND IMAGING}

Baseline laboratory data and imaging findings are shown in Table 2. Not all patients had complete laboratory and imaging data. Lymphopenia was seen in 13 (43\%). Ferritin was elevated in majority of patients. Procalcitonin was elevated in half of patients. C-reactive protein, fibrinogen and D-dimer were likewise elevated. Chest radiograph showed pulmonary infiltrates in all patients, with concomitant consolidation in $23 \%$. Eight (27\%) patients had chest computed tomography (CT), all with ground glass opacities and $62 \%$ with consolidation. There was a disproportionately elevated troponin and N-Terminal proBtype Natriuretic Peptide (NT-proBNP) levels. Echocardiogram obtained in $18(60 \%)$ patients showed normal left ventricular size and systolic function in all except 1 (with preexisting heart failure).

\section{ICU THERAPIES}

ICU therapies and complications are shown in Table 3. All patients required invasive mechanical ventilation; 17 (57\%) were intubated within 24 hours of admission. Twelve (40\%) patients were placed on prone position for at least 16 hours; up to 48 hours in 6 (50\%) patients. Four (13\%) received neuromuscular blockade

Eighteen (60\%) received azithromycin. Fifteen (50\%) received tocilizumab. Twenty-four (80\%) received either hydrocholoroquine or chloroquine (only 10 patients completed 10 days). Thirteen (43\%) received antiviral therapy. Seventeen

\begin{tabular}{|c|c|}
\hline Variable & Overall $(N=30)$ \\
\hline Age, years & $65 \pm 3.0$ \\
\hline Male & $19(63 \%)$ \\
\hline Body mass index, $\mathrm{kg} / \mathrm{m}^{2}$ & $26.63 \pm 1.0$ \\
\hline Normal & $10(33 \%)$ \\
\hline Underweight & $2(7 \%)$ \\
\hline Overweight & $15(50 \%)$ \\
\hline Obese & $3(10 \%)$ \\
\hline \multicolumn{2}{|l|}{ Co-morbidities } \\
\hline Hypertension & $20(67 \%)$ \\
\hline Diabetes mellitus & $13(45 \%)$ \\
\hline Hyperlipidemia & $12(40 \%)$ \\
\hline Heart failure & $1(3 \%)$ \\
\hline Atrial fibrillation & $1(3 \%)$ \\
\hline Coronary artery disease & $1(3 \%)$ \\
\hline Prior myocarditis & $1(3 \%)$ \\
\hline Prior stroke & $1(3 \%)$ \\
\hline Peripheral arterial disease & $1(3 \%)$ \\
\hline Chronic obstructive pulmonary disease & $3(10 \%)$ \\
\hline Asthma & $1(6 \%)$ \\
\hline Chronic kidney disease & $1(3 \%)$ \\
\hline Cancer $^{*}$ & $2(7 \%)$ \\
\hline Current or former tobacco smoker & $10(33 \%)$ \\
\hline \multicolumn{2}{|l|}{ Medications Prior to Admission } \\
\hline Angiotensin-converting enzyme inhibitor & $1(3 \%)$ \\
\hline Angiotensin II receptor blocker & $15(50 \%)$ \\
\hline Calcium channel blockers & $12(40 \%)$ \\
\hline$\geq 2$ Antihypertensive medications & $12(60 \%)$ \\
\hline Oral hypoglycemic agent & $8(27 \%)$ \\
\hline Insulin & $1(3 \%)$ \\
\hline Statins & $12(40 \%)$ \\
\hline Antiplatelet & $7(24 \%)$ \\
\hline \multicolumn{2}{|l|}{ Symptoms on Admission } \\
\hline Dyspnea & $19(63 \%)$ \\
\hline Fever & $17(57 \%)$ \\
\hline Cough & $17(57 \%)$ \\
\hline Body malaise & $17(57 \%)$ \\
\hline Loss of appetite & $5(17 \%)$ \\
\hline Diarrhea & $5(17 \%)$ \\
\hline Sore throat & $3(10 \%)$ \\
\hline Fatigue & $1(3 \%)$ \\
\hline Duration of symptoms prior to admission, days & $7.03 \pm 0.7$ \\
\hline \multicolumn{2}{|l|}{ Vitals on Admission } \\
\hline Temperature $>38$ degrees Celsius & $17(57 \%)$ \\
\hline Respiratory rate $>24$ breaths per minute & $16(53 \%)$ \\
\hline Systolic blood pressure, $\mathrm{mmHg}$ & $127 \pm 4.8$ \\
\hline Diastolic blood pressure, $\mathrm{mmHg}$ & $69.76 \pm 2.4$ \\
\hline Hypotension (blood pressure $<90 / 60 \mathrm{mmHg}$ ) & $3(10 \%)$ \\
\hline Heart Rate (HR), beats per minute (bpm) & $96 \pm 3.9$ \\
\hline Tachycardia (HR >90bpm) & $13(43 \%)$ \\
\hline
\end{tabular}

Continuous variables are expressed as mean $\pm \mathrm{SD}$; categorical variables are expressed as number of patients (percentage)

* Prior treatment for prostate cancer $(n=1)$ and breast cancer $(n=1)$ 


\begin{tabular}{|c|c|}
\hline Variable* & Overall $(N=30)$ \\
\hline Hemoglobin, g/L & $128.73 \pm 2.7$ \\
\hline White blood count, $\times 10^{\wedge} 9 / \mathrm{L}$ & $10.16 \pm 1.5$ \\
\hline Normal Range & $17(57 \%)$ \\
\hline$>10 \times 10^{\wedge} 9 / \mathrm{L}$ & $10(33 \%)$ \\
\hline$<4 \times 10^{\wedge} 9 / \mathrm{L}$ & $3(10 \%)$ \\
\hline Neutrophils & $0.78 \pm 0.02$ \\
\hline$>0.810 \wedge 9 / \mathrm{L}$ & $26(87 \%)$ \\
\hline Lymphocytes x10^9/L & $0.14 \pm 0.02$ \\
\hline$<0.810^{\wedge} 9 / \mathrm{L}$ & $13(43 \%)$ \\
\hline Platelet count & $228.7 \pm 17.4$ \\
\hline Creatinine, $\mathrm{mg} / \mathrm{dL}$ & $1.08 \pm 0.1$ \\
\hline Hemoglobin A1c, \% & $7.675 \pm 0.5$ \\
\hline Lactate $(\mathrm{N}=25) \mathrm{mmol} / \mathrm{L}$ & $1.328 \pm 0.1$ \\
\hline Lactate Dehydrogenase $(\mathrm{N}=26), \mathrm{U} / \mathrm{L}$ & $528.15 \pm 35.3$ \\
\hline Procalcitonin ( $\mathrm{N}=28), \mathrm{ng} / \mathrm{mL}$ & $1.16 \pm 0.3$ \\
\hline$>/=0.5$ & $14(50 \%)$ \\
\hline Ferritin ( $\mathrm{N}=27), \mathrm{ng} / \mathrm{mL}$ & $1428.11 \pm 216.6$ \\
\hline$>464$ & $23(85 \%)$ \\
\hline C-Reactive Protein $(\mathrm{N}=21), \mathrm{mg} / \mathrm{L}$ & $220.84 \pm 36.3$ \\
\hline$>3$ & $21(100 \%)$ \\
\hline D-Dimer ( $\mathrm{N}=8), \mathrm{ug} / \mathrm{ml}$ & $2.75 \pm 0.5$ \\
\hline$>0.5$ & $7(88 \%)$ \\
\hline Fibrinogen $(\mathrm{N}=6), \mathrm{mg} / \mathrm{dl}$ & $642.33 \pm 92.6$ \\
\hline$>350$ & $6(100 \%)$ \\
\hline High-sensitivity cardiac troponin I $(\mathrm{N}=20), \mathrm{pg} / \mathrm{mL}$ & $483.39 \pm 288.1$ \\
\hline NT-ProBNP pg/mL (N=20) & $5798.45 \pm 2418.3$ \\
\hline \multicolumn{2}{|l|}{ Echocardiography $(\mathrm{N}=18)$} \\
\hline \multicolumn{2}{|l|}{ Left Ventricular Ejection Fraction (LVEF) } \\
\hline LVEF >50\% & $17(94 \%)$ \\
\hline LVEF $<50 \%$ & $1(6 \%)$ \\
\hline \multicolumn{2}{|l|}{ Electrocardiogram on admission } \\
\hline Sinus rhythm & $29(96 \%)$ \\
\hline Atrial fibrillation & $1(3 \%)$ \\
\hline Corrected QT (QTc), msec & $448.9 \pm 7.0$ \\
\hline \multicolumn{2}{|l|}{ Chest radiography } \\
\hline Infiltrates only & $19(63 \%)$ \\
\hline Infiltrates + Pleural effusion & $4(13 \%)$ \\
\hline Infiltrates + Consolidation & $7(23 \%)$ \\
\hline \multicolumn{2}{|l|}{ Chest computed tomography $(\mathrm{N}=8)$} \\
\hline Ground Glass & $2(25 \%)$ \\
\hline Ground Glass + Pleural effusion & $1(13 \%)$ \\
\hline Ground Glass + Pleural effusion + Consolidation & $1(13 \%)$ \\
\hline Ground Glass + Consolidation & $4(50 \%)$ \\
\hline \multicolumn{2}{|l|}{ Positive Cultures } \\
\hline Blood $(n=30)$ & $12 / 30(40 \%)$ \\
\hline Endotracheal aspirate/sputum ( $\mathrm{N}=22)$ & $17 / 22(77 \%)$ \\
\hline Urine $(n=8)$ & $7 / 8(88 \%)$ \\
\hline \multicolumn{2}{|l|}{ Organisms Identified on Cultures $(\mathrm{N}=60)$} \\
\hline Candida albicans $\$^{\$}$ & $17 / 60(28 \%)$ \\
\hline Acinetobacter baumannii ${ }^{\$ \$}$ & $4 / 60(7 \%)$ \\
\hline Klebsiella pneumoniae ${ }^{\$ \$ \$}$ & $6 / 60(10 \%)$ \\
\hline
\end{tabular}

Continuous variables are expressed as mean $\pm \mathrm{SD}$; categorical variables are expressed as number of patients (percentage)

* Not all patients had complete laboratory and imaging data

$\$$ Identified from blood (5/30), endotracheal aspirate/sputum (9/22), urine (6/8) cultures

$\$ \$$ Identified from blood (1/30) and endotracheal/sputum aspirate (3/22) cultures

$\$ \$ \$$ Identified from blood (2/30) endotracheal culture(6/22)
(47\%) received steroids. Four (13\%) received intravenous immunoglobulin. Twenty nine (97\%) received venous thromboembolism (VTE) prophylaxis with either low molecular weight heparin or unfractionated heparin (UFH), depending on renal function.

Sepsis was seen in all patients and $87 \%$ had septic shock. All patients received antibiotics. The predominant organisms identified on cultures were Candida albicans, Klebsiella pneumoniae and Acinetobacter baumanii (Table 2). Bleeding requiring transfusion was seen in 7 (23\%) patients. Fourteen (47\%) patients required renal replacement therapy.

\section{PREDICTORS OF MORTALITY}

There were 22 (73\%) who died, 6 (20\%) discharged improved, $1(3 \%)$ transferred to another hospital (outcome unknown), and $1(3 \%)$ still admitted in the hospital at the time this study was written (Table $\mathbf{3}$ ). Comparison of clinical characteristics and outcomes are shown in Table 4. Norepinephrine plus vasopressin and UFH therapies were significantly higher among non-survivors versus survivors. The mean number of days admitted at the hospital was significantly higher among survivors versus non-survivors (excluding 1 patient still admitted). Although not significant, there was a trend towards a higher mean troponin and NT-proBNP among non-survivors versus survivors. There was also a nonsignificant trend towards a shorter mean duration of symptoms prior to consult among survivors versus non-survivors.

On univariate analysis (Table 5), norepinephrine plus vasopressin and UFH therapies were associated with increased mortality. Mean duration from ICU admission to death was 13 days for non-survivors. We found that troponin and NT-proBNP were not associated with increased mortality. On multivariate analysis (Table 6), we did not expect to find significant interactions with mortality given with our small sample size.

\section{DISCUSSION}

We report 30 confirmed COVID-19 patients with ARDS who required mechanical ventilation and ICU care during the first month of the outbreak in Metro Manila. Mortality was 73\%, higher compared to previous studies on critically ill COVID-19 patients. We found the mean survival time of non-survivors is likely to be 13 days after ICU admission. In the study by Yang et al, 71\% required mechanical ventilation, mortality was $61.5 \%$ and median duration from ICU admission to death was 7 (IQR 3-11) days. Bhatraju et al reported that $75 \%$ required mechanical ventilation and mortality was $50 \%$. In the largest cohort of COVID-19 patients from China, ${ }^{4} 5 \%$ were identified as critical with a case fatality rate of $49 \%$.

We found the use of norepinephrine plus vasopressin was associated with increased mortality. In our cohort, all patients developed sepsis and majority developed shock that required vasopressor support. Similar to Bhatraju et al, we did not find evidence of left ventricular dysfunction (except in 1 with preexisting heart failure) in those who had an echocardiogram. In the study by Zhou et al, sepsis was the most common complication; septic shock was seen in $20 \%$ of patients, all of whom died..$^{13}$ Yang et al and Bhatraju et al reported vasopressor use in $35 \%$ and $71 \%$ of patients, respectively. 


\begin{tabular}{|c|c|}
\hline & $\mathrm{N}(\%)$ \\
\hline \multicolumn{2}{|l|}{ ICU Therapies } \\
\hline Mechanical Ventilation & $30(100 \%)$ \\
\hline On admission & $6(20 \%)$ \\
\hline Within 24 hours & $11(37 \%)$ \\
\hline$>24$ hours & $13(43 \%)$ \\
\hline Unfractionated Heparin & $29(97 \%)$ \\
\hline Low Molecular Weight Heparin & $14(47 \%)$ \\
\hline Novel Oral Anticoagulants & $1(3 \%)$ \\
\hline Lopinavir + Ritonavir & $9(30 \%)$ \\
\hline Oseltamivir & $4(13 \%)$ \\
\hline Hydrochloroquine & $10(33 \%)$ \\
\hline Chloroquine & $14(47 \%)$ \\
\hline Tocilizumab & $15(50 \%)$ \\
\hline Intravenous Immunoglobulins & $4(13 \%)$ \\
\hline Azithromycin & $18(60 \%)$ \\
\hline Antibiotics & $30(100 \%)$ \\
\hline Steroids & $14(47 \%)$ \\
\hline \multicolumn{2}{|l|}{ Vasopressors } \\
\hline Norepinephrine & $26(87 \%)$ \\
\hline Vasopressin & $17(57 \%)$ \\
\hline Epinephrine & $2(7 \%)$ \\
\hline Dobutamine & $1(3 \%)$ \\
\hline Dopamine & $1(3 \%)$ \\
\hline Neuromuscular blockade & $4(13 \%)$ \\
\hline Continuous Renal Replacement Therapy & $14(47 \%)$ \\
\hline Prone position & $12(40 \%)$ \\
\hline 16 hours & $2(17 \%)$ \\
\hline 24 Hours & $4(33 \%)$ \\
\hline 48 hours & $6(50 \%)$ \\
\hline \multicolumn{2}{|l|}{ Complications } \\
\hline Sepsis & $30(100 \%)$ \\
\hline Septic Shock & $26(87 \%)$ \\
\hline Bacteremia & $12(40 \%)$ \\
\hline \multicolumn{2}{|l|}{ Arrhythmias } \\
\hline Ventricular Tachycardia & $3(10 \%)$ \\
\hline Atrial Fibrillation & $7(23 \%)$ \\
\hline Unstable Bradycardia & $4(13 \%)$ \\
\hline \multicolumn{2}{|l|}{ Bleeding } \\
\hline Upper Gastrointestinal & $8(27 \%)$ \\
\hline IJ site bleeding & $1(3 \%)$ \\
\hline Transfusion Requiring & $7(23 \%)$ \\
\hline \multicolumn{2}{|l|}{ Outcomes } \\
\hline Died in hospital & $22(73 \%)$ \\
\hline Discharged from Hospital & $6(20 \%)$ \\
\hline Still admitted & $1(3 \%)$ \\
\hline Transferred & $1(3 \%)$ \\
\hline
\end{tabular}

Categorical variables are expressed as number of patients (percentage) *Sepsis and septic shock were defined according to the Surviving Sepsis Guidelines
In our cohort, those with procalcitonin and CRP had elevated levels in 50\% and $100 \%$, respectively. Candida albicans, Klebsiella pneumoniae and Acinetobacter baumanii were the predominant organisms identified on cultures. Our findings suggest that the observed shock may be due to bacterial/fungal co-infection. Rawson et al reviewed current literature surrounding bacterial/fungal co-infection in patients with coronavirus infection. Of 9 studies reporting bacterial co-infection in COVID-19 cases, $62 / 806(8 \%)$ cases of bacterial/fungal co-infection were reported; $72 \%$ of COVID-19 cases received antibacterial therapy. ${ }^{21}$ The pathogenesis of sepsis, as well as bacterial/fungal co-infection and use of broad-spectrum empirical antibiotics in COVID-19 needs further investigation.

Although no screening was performed, VTE was not observed in our cohort. Nearly all patients were given anticoagulation for VTE prophylaxis. Interestingly, we found that UFH for VTE prophylaxis was associated with increased mortality. The mechanism of this increased mortality is uncertain, as we did not see a significant increase in bleeding, including major bleeding requiring blood transfusion. In a study by Maatman et al, 31 (28\%) of 109 COVID-19 patients admitted in the ICU developed VTE despite almost all being on heparin thromboprophylaxis. There was no difference in mortality among patients who developed VTE compared to those without VTE. ${ }^{22}$

Cardiac injury and heart failure have been reported among patients hospitalized with COVID-19. ${ }^{13,23-24}$ In a meta-analysis by Santoso et al, cardiac injury was associated with mortality, need for ICU care and severity of disease in patients with COVID-19. ${ }^{25}$ In one report of 4 fatal COVID-19 cases, ${ }^{26}$ only focal mild fibrosis and mild myocardial hypertrophy were seen on postmortem needle core biopsy of the heart, changes likely related to their underlying diseases. In another report of 1 COVID-19 patient with cardiogenic shock, viral particles were seen on endomyocardial biopsy, likely due to a viremic phase or macrophage migration from the lungs. ${ }^{27}$

The mechanisms of cardiac injury is still not clear, and data on the incidence of heart failure is limited. In the sex-, age-, and comorbid illness-matched case control study of Du et al, they found CD3+CD8+ T cells $\leq 75$ cell/ $\mu \mathrm{L}$ and cardiac troponin I $\geq 0.05 \mathrm{ng} / \mathrm{mL}$ were predictors for high mortality of COVID-19 pneumonia patients with similar age and underlying diseases. ${ }^{28}$ They note that the elevation of cardiac troponin I in COVID-19 patients was just indicative of myocardial injury that was probably secondary to severe hypoxemia. We found, in contrast to previous studies, a nonsignificant trend towards a higher mean troponin and NT-proBNP levels among non-survivors versus survivors. In our cohort, all patients had ARDS requiring mechanical ventilation. In addition, there was no predominance of cardiovascular disease and in those with echocardiogram, all (except one with preexisting heart failure), had normal systolic function on echocardiogram. Severe hypoxemia from ARDS may have contributed to the elevated troponin and NT-proBNP.

Except for the use of UFH and norepinephrine plus vasopressin support, we did not see a difference in mortality for the different ICU therapies, including antimalarials and prone position. Prone position, done in almost half our patients, had no benefit and even showed a trend for higher mortality among those proned for up to 48 hours. This may be explained by the dissociation between relatively preserved lung mechanics and the severity of hypoxemia, resulting in an atypical form of the syndrome despite fulfilling criteria for ARDS. ${ }^{29}$ 


\begin{tabular}{|c|c|c|c|}
\hline Variables* & $\begin{array}{c}\text { Non-Survivors } \\
\qquad=22\end{array}$ & $\begin{array}{c}\text { Survivors } \\
\quad N=8\end{array}$ & $P$ value \\
\hline \multicolumn{4}{|l|}{ Demographics } \\
\hline Age (mean) & 67 & 60 & 0.263 \\
\hline Males & 13 & 6 & 0.672 \\
\hline BMI (mean) & 27 & 27 & 0.960 \\
\hline Hypertension & 14 & 6 & 0.682 \\
\hline Diabetes mellitus & 11 & 2 & 0.283 \\
\hline Smoking history & 5 & 3 & 0.658 \\
\hline Number of days in the hospital ${ }^{\$}$ & $22(12.9)$ & $7(31)$ & 0.001 \\
\hline Onset of Symptoms (Days) & $22(7.4)$ & $8(6)$ & 0.397 \\
\hline \multicolumn{4}{|l|}{ Laboratories } \\
\hline WBC Count & $22(11.01)$ & $8(7.82)$ & 0.347 \\
\hline$>10 \times 10^{\wedge} 9 / \mathrm{L}$ & 9 & 1 & 0.330 \\
\hline Neutrophil count $>0.8 \times 10^{\wedge} 9 / \mathrm{L}$ & $21(0.79)$ & $8(0.77)$ & 0.656 \\
\hline Lymphocyte count $<0.8 \times 10^{\wedge} \mathrm{g} / \mathrm{L}$ & $21(0.13)$ & $8(0.15)$ & 0.629 \\
\hline HBa1c & $11(8.15)$ & $5(6.62)$ & 0.159 \\
\hline Procalcitonin & $20(1.18)$ & $8(1.09)$ & 0.888 \\
\hline CRP & $14(231.89)$ & $7(198.76)$ & 0.678 \\
\hline Ferritin & $19(1479)$ & $8(1305)$ & 0.722 \\
\hline Lactate & $19(1.43)$ & $6(1)$ & 0.131 \\
\hline D Dimer & $5(3.36)$ & $3(1.73)$ & 0.125 \\
\hline Troponin & $14(654)$ & $6(85)$ & 0.379 \\
\hline NT-Pro-BNP & $14(6898)$ & $6(3232)$ & 0.502 \\
\hline \multicolumn{4}{|l|}{ Chest Xray } \\
\hline Infiltrates + Consolidation & 6 & 1 & 0.833 \\
\hline \multicolumn{4}{|l|}{ Chest CT } \\
\hline Ground Glass + Consolidation & 3 & 1 & 0.286 \\
\hline Corrected QT Interval, msec & $22(452.5)$ & $8(438.87)$ & 0.399 \\
\hline \multicolumn{4}{|l|}{ Echocardiography } \\
\hline Left Ventricular Ejection Fraction & $13(57.64)$ & $5(57.96)$ & 0.953 \\
\hline
\end{tabular}

\section{ICU Therapies•}

Anticoagulation

\begin{tabular}{|c|c|c|c|}
\hline Unfractionated Heparin & 22 & 7 & 0.012 \\
\hline Low Molecular Weight Heparin & 9 & 5 & 0.417 \\
\hline Lopinavir + Ritonavir & 8 & 1 & 0.374 \\
\hline Oseltamivir & 2 & 2 & 0.284 \\
\hline Tociluzimab & 11 & 4 & ** \\
\hline \multicolumn{4}{|l|}{ Anti-malarial } \\
\hline Hydrochloroquine & 6 & 4 & 0.384 \\
\hline Chloroquine & 11 & 3 & 0.689 \\
\hline Days on Chloroquine & $10(7.1)$ & $3(7.33)$ & 0.926 \\
\hline Days on Hydrochloroquine & $6(6.5)$ & $2(8.5)$ & 0.570 \\
\hline Azithromycin & 12 & 5 & 0.407 \\
\hline Antibiotics & 22 & 8 & 4 \\
\hline Steroids & 9 & 5 & 0.645 \\
\hline \multicolumn{4}{|l|}{ Vasoactive Agents } \\
\hline Vasopressin + Norepinephrine & 16 & 1 & 0.009 \\
\hline Norepinephrine & 19 & 7 & ** \\
\hline Neuromuscular blockade & 5 & 0 & 0.290 \\
\hline Continuous renal replacement therapy & 14 & 1 & 0.215 \\
\hline Proning & 9 & 3 & 0.136 \\
\hline 16 Hours & 2 & 0 & \\
\hline 24 Hours & 2 & 3 & \\
\hline 48 Hours & 5 & 0 & \\
\hline
\end{tabular}

Some limitations should be recognized. First, because we focused on COVID-19 patients with critical illness, our sample size was small. Second, since this was an observational study, not all patients had complete baseline laboratory and imaging tests performed. Finally, our cohort may have an underestimated mortality. At the time our study was written, 1 patient remained admitted at the hospital and 1 patient transferred to another hospital with unknown outcome data.

The clinical course and outcomes of critically ill COVID-19 patients during the first month of the outbreak in Metro Manila are similar to reports from other countries. The mortality of our cohort was high at $73 \%$. We report the use of norepinephrine plus vasopressin and UFH for VTE prophylaxis were predictors of increased mortality among critically ill COVID-19 patients. Mean survival time of nonsurvivors is likely to be 13 days after ICU admission. We report that elevated troponin and NT-proBNP were not associated with increased mortality. Our findings suggest that those patients who eventually died had greater hemodynamic instability and thus required more vasopressor support. We can conclude that critically ill COVID-19 patients who require inotropic support are at increased risk of death. Although we believe our findings may help guide clinical decision making in COVID-19 patients requiring ICU care, caution must be applied when interpreting results presented here in view of our small cohort.

\section{FUNDING}

None

The authors have no conflicts of interest to disclose.

\section{KEYWORDS}

COVID-19, Critically III, Predictors of Mortality

\section{REFERENCES}

1. Coronavirus disease (COVID-19) in the Philippines. World Health Organization https:// www.who.int/philippines

2. Department of Health, Republic of the Philippines. www.doh.gov.ph/covid-19/case-tracker

3. Center for Strategic and International Studies, Southeast Asia Covid-19 tracker, 2020. https:// www.csis.org

4. Wu Z, McGoogan JM. Characteristics of and important lessons from the coronavirus disease 2019 (COVID-19) out- break in China: summary of 


\begin{tabular}{|c|c|c|c|}
\hline Variables* & $\begin{array}{c}\text { Non-Survivors } \\
\mathrm{N}=22\end{array}$ & $\begin{array}{c}\text { Survivors } \\
\qquad N=8\end{array}$ & $P$ value \\
\hline \multicolumn{4}{|l|}{ Complications• } \\
\hline Sepsis & 22 & 8 & 0.757 \\
\hline Septic shock & 19 & 7 & 0.284 \\
\hline \multicolumn{4}{|l|}{ Arrhythmia } \\
\hline Ventricular tachycardia & 3 & 0 & 0.50 \\
\hline Bleeding requiring transfusion & 4 & 4 & 0.158 \\
\hline
\end{tabular}

* values are reported as number of patients (mean)

\$ data did not include 1 patient still admitted

** $p$ value is 1.000

a $p$ value cannot be determined

\begin{tabular}{|c|c|c|c|c|}
\hline Variables* & $\begin{array}{l}\text { Non-Survivors } \\
\qquad \mathrm{N}=22\end{array}$ & $\begin{array}{c}\text { Survivors } \\
\mathrm{N}=8\end{array}$ & $\begin{array}{c}\text { Odds Ratio } \\
\text { (95\% CI) }\end{array}$ & $P$ value \\
\hline \multicolumn{5}{|l|}{ Demographics } \\
\hline Diabetes mellitus & 11 & 2 & 3 & 0.233 \\
\hline \multicolumn{5}{|l|}{ Laboratories } \\
\hline HBa1c & $11(8.15)$ & $5(6.62)$ & 2.17 & 0.193 \\
\hline Lactate & $19(1.43)$ & $6(1)$ & 16.3 & 0.106 \\
\hline D Dimer & $5(3.36)$ & $3(1.73)$ & 2.9 & 0.146 \\
\hline Troponin I & $14(654)$ & $6(85)$ & $\begin{array}{c}1.00 \\
(0.99-1.01)\end{array}$ & 0.335 \\
\hline $\mathrm{BNP}$ & $14(6898)$ & $6(3232)$ & $\begin{array}{c}1.00 \\
(0.99-1.0002)\end{array}$ & 0.393 \\
\hline Days in hospital & $22(12.9)$ & $7(31)$ & $\begin{array}{c}0.9 \\
(0.83-0.97)\end{array}$ & 0.011 \\
\hline Anticoagulation (UFH) & 22 & 7 & $\begin{array}{c}10.2 \\
(1.54-67.21)\end{array}$ & 0.016 \\
\hline Vasopressin + Norepinephrine & 16 & 1 & $\begin{array}{c}3.4 \\
(1.01-5.91)\end{array}$ & 0.006 \\
\hline
\end{tabular}

Table 6. Predictors of Mortality (Multivariate Analysis)

\begin{tabular}{lcc} 
Variables* & Odds Ratio $\mathbf{( 9 5 \% ~ C l )}$ & $\boldsymbol{P}$ value \\
$\begin{array}{l}\text { Demographics } \\
\text { Age }\end{array}$ & $0.94(0.65-1.36)$ & 0.771 \\
\hline Diabetes mellitus & $6.81(0.002-22288.78)$ & 0.642 \\
\hline $\begin{array}{l}\text { Laboratories } \\
\text { HBa1c }\end{array}$ & $0.14(0.00006-302.81)$ & 0.618 \\
\hline Lactate & $627(9.15-4.30)$ & 0.484 \\
\hline Troponin I & $1.01(0.96-1.06)$ & 0.601
\end{tabular}

\section{Table 4. Comparison of Clinical Characteristics and Outcomes}

-missing data for 1 patient who was transferred to another hospital

11. Wu C, Chen X Cai Y, et al. Risk factors associated with acute respiratory distress syndrome and death in patients with coronavirus disease 2019 pneumonia in Wuhan, China. JAMA Intern Med 2020; [Epub ahead of print]

12. Yang $X, Y u Y, X u J$, et al. Clinical course and outcomes of critically ill patients with SARSCoV-2 pneumonia in Wuhan, China: a singlecentered, retrospective, observational study. Lancet Respir Med 2020;8:475-481.

13. Zhou, F et al Clinical course and risk factors for mortality of adult inpatients with COVID-19 in Wuhan, China: a retrospective cohort study. Lancet 2020;395:1054-1062

14. Bhatraju P, Ghassemieh B, Nichols M, et al. Covid-19 in critically ill patients in the Seattle region - case series. N Engl J Med 2020;382:2012-2022.

15. Long B, Brady W. Gottlieh M, et al Cardiovascular complications in COVID-19. Am J Emerg Med. 2020; [Epub ahead of print]

16. Interim guidelines for collecting, handling, and testing clinical specimens from persons for coronavirus disease 2019 (COVID-19). Centers for Disease Control and Prevention 2020. https:// www.cdc.gov

17. Ranieri VM, Rubenfeld G, Thompson BT, et al Acute respiratory distress syndrome: the Berlin definition. JAMA 2012;307:2526-2533.

18. Chinese clinical guidance for COVID-19 pneumonia diagnosis and treatment (7th edition). http://kjfy.meetingchina.org/msite/news/show/ $\mathrm{cn} / 3337 . \mathrm{html}$

19. Rhodes A, Evans L, Alhazzani W, et al. Surviving Sepsis Campaign: International Guidelines for Management of Sepsis and Septic Shock: 2016. Critical Care Medicine 2017;45:486-552.

20. Von Elm E, Altman DG, Egger M, et al. The Strengthening the Reporting of Observational Studies in Epidemiology (STROBE) statement: guidelines for reporting observational studies. Lancet 2007;370:1453-1457.

21. Rawson TM, Moore LSP, Zhu N, et al. Bacterial and fungal co-infection in individuals with coronavirus: A rapid review to support COVID-19 antimicrobial prescribing. Clinical Infectious Diseases 2020; [Epub ahead of print]

22. Maatman $T$, Jalali F, Feizpour $C$, et al. Routine Venous Thromboembolism Prophylaxis May Be Inadequate in the Hypercoagulable State of Severe Coronavirus Disease 2019. Critical Care Medicine 2020; [Epub ahead of print]

23. Shi S, Qin M, Shen B et al. Association of cardiac injury with mortality in hospitalized patients with COVID-19 in Wuhan, China. JAMAA Cardiol 2020; [Epub ahead of print]

24. Chen T, Wu D, Chen $\mathrm{H}$ et al. Clinical characteristics of 113 deceased patients with coronavirus disease 2019: retrospective study. BMJ 2020;368:[Epub ahead of print]

25. Santoso A, Pranata R, Wibowo A, et al. Cardiac injury is associated with mortality and critically ill

a report of 72314 cases from the Chinese Center for Disease Control and Prevention. JAMA 2020;323:1239-1242.

5. Richardson S, Hirsch J. Narasimhan M, et al. Presenting characteristics, comorbidities, and outcomes among 5700 patients hospitalized with COVID-19 in the New York City area. JAMA 2020;323:2052-2059.

6. Richardson S, Hirsch J. Narasimhan M, et al. Clarification of mortality rate and data in abstract, results, and table 2. JAMA 2020;323:2098.

7. Guan WJ, Ni ZY, Hu Y, et al. Clinical characteristics of coronavirus disease 2019 in China. N Engl J Med 2020;382:1708-1720.

8. Chen N, Zhou M, Dong X, et al. Epidemiological and clinical characteristics of 99 cases of 2019 novel coronavirus pneumonia in Wuhan, China: a descriptive study. Lancet 2020;395:507-513.

9. Huang C, Wang Y, Li X, et al. Clinical features of patients infected with 2019 novel coronavirus in Wuhan, China. Lancet 2020;395:497-506.

10. Wang D, Hu B, Hu C, et al. Clinical characteristics of 138 hospitalized patients with 2019 novel coronavirus-infected pneumonia in Wuhan, China. JAMA. 2020;23:1061-1069. pneumonia in COVID-19: A meta-analysis. Am J Em Med 2020: April 14th https://doi.org/10.1016/j.ajem.2020.04.052.

26. Tian S, Xiong Y, Liu H et al. Pathological study of the 2019 novel coronavirus disease (COVID-19) through postmortem core biopsies. Modern Pathology 2020;33:1007-1014.

27. Tavazzi G, Pellegrini C, Maurelli M et al. Myocardial localization of coronavirus in COVID-19 cardiogenic shock. European Journal of Heart Failure 2020; [Epub ahead of print]

28. Du, Rong-Hui et al. Predictors of mortality for patients with COVID-19 pneumonia caused by SARS-CoV-2: a prospective cohort study. Eur Respir J. 2020; doi: 10.1183/13993003.00524-2020

29. Gattinoni L, Coppola S, Cressoni M, et al. COVID-19 Does Not Lead to a "Typical" Acute Respiratory Distress Syndrome. American Journal of Respiratory and Critical Care Medicine 2020;201:1299-1300. 